\title{
O ÊXODO DOS JOVENS RURAIS, A TEORIA DO BEM VIVER E A RESISTÊNCIA DA COMUNIDADE REMANESCENTE DE QUILOMBO DO IBICUÍ D'ARMADA, NA FRONTEIRA DO RS
}

\section{The exotus of rural young people, the theory of well living and the resistance of the remaining Community of quilombo do Ibicuí d'Armada, in fronteira do RS}

Rosemeri da Silva Madrid Universidade Federal do Pampa - UNIPAMPA - RS

Margarete Lesina Lopes Gonçalves Universidade Federal do Rio Grande do Sul - UFRGS - RS

Informações do artigo

Recebido em 22/08/2020 Aceito em 08/09/2020

doi>: https://doi.org/10.25247/2447-861X.2020.n251.p567-586

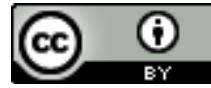

Esta obra está licenciada com uma Licença Creative Commons Atribuição 4.0 Internacional.

\section{Como ser citado (modelo ABNT)}

MADRID, Rosemeri da Silva; GONÇALVES, Margarete Lesina Lopes. O êxodo dos jovens rurais, a Teoria do Bem Viver e a resistência da comunidade remanescente de Quilombo do Ibicuí d'ARMADA, na fronteira do RS. Cadernos do CEAS: Revista Crítica de Humanidades. Salvador/Recife, v. 45, n. 251, p. 567-586, set./dez. 2020. DOI: https://doi.org/10.25247/2447-861X.2020.n251.p567-586

\begin{abstract}
Resumo
O presente artigo tem por objetivo compreender os processos de resistência e perenidade das famílias do território quilombola do Ibicuí d'Armada, localizado no município de Sant'Ana do Livramento na fronteira oeste do RS. Para atingir este objetivo foi adotada abordagem qualitativa, com entrevistas com um grupo de jovens moradores da comunidade e a liderança local. Tomando por base as teorias das capacitações e a teoria do Bem Viver, conclui-se que a comunidade remanescente quilombola possui extrema riqueza cultural e histórica para o município, possuindo potencial ainda não explorado para alavancar desenvolvimento rural, cultural, social e humano, mas que, se não houver ações efetivas neste sentido, o território corre sério risco de se extinguir.

Palavras-Chave: Comunidade quilombola. Jovens rurais. Território Negro. Desenvolvimento.

\section{Abstract}

This article aims to understand the processes of resistance and perpetuity of families in the quilomnola territory of Ibicuí d'Armada, located in the municipality of Sant'Ana do Livramento on the western border of RS. To achieve this objetctive, a qualitative approach was adopted, with interviews winth a group of young residentes of the community and the local leadership. Based on the theories of training and the theory of Well Living, it is concluded that the remaining quilombola community has extreme cultural and historical wealth for the municipality, having untapped potential to leverage rural, cultural, social and human development, but that, if there are no effectie actions in this regard, the territory is in serious danger of becoming extinct.

Keywords: Quilombola community. Rural youth. Black territory. Development.
\end{abstract}

\section{Introdução}

A presença de povos tradicionais no pampa gaúcho se confunde com a história do próprio pampa. Entre estes povos, identifica-se, considerando o aspecto conceitual e sociológico, as comunidades quilombolas e comunidades negras remanescentes de quilombo, entendidas como grupo social local, que desenvolve dinâmicas temporais de 
vinculação a um espaço físico que se torna território coletivo pela transformação da natureza por meio do trabalho de seus fundadores, como bem resgatam Brandão (2010) e Rodrigues, Guimarães e Costa (2011).

Estas mesmas comunidades, embora com amparo institucional ancorado em políticas públicas de reconhecimento e titulação, têm sua sobrevivência e resistência ameaçada por um cenário contemporâneo de retração no apoio a estas comunidades, bem como ao êxodo dos jovens remanescentes de quilombo que, em seus processos de tomada de decisão, muitas vezes são levados a abandonar o campo em busca de oportunidade de emprego ou continuidade nos estudos.

Este quadro é dissonante da ideia de desenvolvimento abordada por Sen (2010) que pode ser visto como um processo de expansão das liberdades, os quais exigem que se removam as principais fontes de privações, enquanto que os jovens remanescentes de quilombo não têm, muitas vezes, a liberdade para fazer suas escolhas, sendo levados, por questões sociais e econômicas, a deixar o campo, comprometendo, com esta decisão, a perenidade das comunidades quilombolas, em especial a comunidade remanescente de quilombo do Ibicuí d'Armada, localizada no município de Sant'Ana do Livramento, fronteira oeste do Rio Grande do Sul.

A percepção, neste contexto, é de que a existência destes grupos sociais esteja condicionada a fatores econômicos, conforme a ideia de Polanyi (1980), segundo a qual a economia do homem está submersa em suas relações sociais [...] e ele age assim para salvaguardar sua situação social, suas exigências sociais, o que levaria os jovens rurais a uma situação de êxodo do campo.

O município de Sant'Ana do Livramento tem uma área territorial total de 6.941,399 km2 (IBGE, 2019),

o que o faz o segundo maior município em área no estado do Rio Grande do Sul. E Sant'Ana do Livramento possui área rural dividida em sete distritos, conforme dispõe a Lei Municipal 2.555, de 29 de novembro de 1989. Uma destas áreas é o terceiro distrito do Ibicuí d'Armada, localizado às margens do Rio Ibicuí da Cruz, fazendo divisa com o município de Dom Pedrito.

Dentro desta área de terra, são residentes, segundo o último Censo Demográfico do Instituto Brasileiro de Geografia e Estatística - IBGE, trinta e uma famílias descendentes de escravos alforriados, que receberam do Governo Federal, através da Fundação Cultural 
Palmares, a certidão de auto definição, conforme dispõem vários preceitos legais, sendo reconhecidos legalmente como remanescentes de quilombo.

Mesmo amparados pela Constituição Federal, em especial às leis infraconstitucionais, decretos, portarias e instruções normativas de caráter afirmativo, estas comunidades ainda estão à margem de políticas públicas que incentivem o desenvolvimento local e o empreendedorismo e, conforme corroborado pela pesquisa deste estudo, a comunidade tem desconhecimento e ausência de orientação técnica institucional para desencadear, com autonomia, o processo de sustentabilidade econômica.

Em âmbito nacional, o Governo Federal, desde 2004 vinha implementando uma série de ações destinadas a esta parcela da população, considerada prioritária dentro dos programas sociais, destacando o Plano Brasil sem Miséria, Programa Luz para Todos e Programa Água para Todos (BRASIL), inserindo, ainda, nas peças orçamentárias da União, como Plano Plurianual - PPA -, Lei de Diretrizes Orçamentárias - LDO - e o próprio Orçamento, programas, indicadores e metas e serem atingidas para promoção da inclusão social das comunidades remanescentes de quilombo, ancorados na Lei Federal 12.888, de 20 de julho de 2010 (Estatuto da Igualdade Racial).

Conforme regulamenta a Instrução Normativa Federal no 49, de 29 de setembro de 2008, em vigência até então, são considerados remanescentes de quilombos os grupos étnicos raciais, conforme critérios de auto definição, com trajetória histórica própria, dotados de relações territoriais específicas, com presunção de ancestralidade negra relacionada com a resistência à opressão histórica sofrida. Para confirmar a condição de comunidade remanescente de quilombo, os moradores do Ibicuí d'Armada foram investigados por técnicos da Emater/RS-ASCAR, que é a instituição à frente do serviço oficial de extensão rural do estado gaúcho e representantes do Conselho Estadual de Desenvolvimento da Comunidade Negra - CODENE, acompanhados pela antropóloga Rosane Aparecida Hubert.

Mesmo com o reconhecimento federal e pela importância histórica e cultural que os quilombolas representam, a existência desta comunidade é pouco conhecida entre os moradores urbanos de Sant'Ana do Livramento. Existe um leque de possibilidades de inserção destas pessoas, através de políticas públicas voltadas à proteção e preservação das comunidades quilombolas, ainda não praticadas pelo poder público local, conforme comprovado em pesquisa de Madrid e Adão (2016). 
Além disso, as comunidades tradicionais, com suas dinâmicas próprias, compreendem que têm conceituação ancorada em elementos do campo dos direitos consuetudinários, da ideia de que a presença em um território por longo tempo gera direitos aos sujeitos, que o modo de vida demarca diferenças; que a consciência da diferença promove a ação política da identidade (THUM, 2017).

Para comprovar a existência de ações empreendedoras institucionais, capazes de desencadear o desenvolvimento local da comunidade rural do Ibicuí d'Armada, bem como identificar o perfil sócio econômico destes moradores e sua cultura empreendedora, que servem de diretriz para identificar as condições de resistência deste grupo social, já foram feitos trabalhos junto às famílias do Ibicuí (MADRID; ADÃO, 2016) nos quais houve inserção no cotidiano rural e o estabelecimento do compartilhamento de experiências, narrativas, recortes nostálgicos dos moradores mais longevos, que fizeram um mergulho na sua ancestralidade, revelando orgulho de seus antepassados e elencando as conquistas estabelecidas ao longo das décadas.

Com estas considerações, este trabalho tem por objetivo compreender os processos de resistência e perenidade das famílias do território negro quilombola do Ibicuí d'Armada, na fronteira oeste do Rio Grande do Sul, considerando o elevado êxodo rural dos jovens. Para atingir o referido objetivo foi adotada a abordagem qualitativa, a partir de entrevistas com grupo de doze jovens moradores da comunidade remanescente de quilombo e, ainda, com a moradora daquela localidade que exerce liderança naquele território.

Este trabalho faz uso também da pesquisa documental, especialmente documentos como livros, periódicos, artigos científicos e a legislação, no que tange às questões de proteção do território das comunidades tradicionais, pesquisa interpretativa, entre outras. A maior preocupação é obter uma descrição densa, a mais completa possível, sobre o que um grupo particular de pessoas faz e o significado das perspectivas imediatas do que eles têm sobre o que eles fazem (MATTOS, 2011), dentro do contexto do território rural negro.

A coleta de dados aconteceu a partir da imersão das pesquisadoras no ambiente de pesquisa, entrevistando os integrantes da comunidade, interagindo com aqueles atores e observando o seu modo de vida, costumes, ofícios, enfim, todas as informações que venham a subsidiar o presente estudo, atendendo aos seus objetivos. 


\section{Tomada de decisão dos jovens rurais negros}

A presença, em um território, de uma comunidade tradicional, como os indígenas, ribeirinhos, quilombolas e sua trajetória de saberes e conhecimentos, repassados ancestralmente de geração após geração, está fortemente ligada ao desenvolvimento, considerando que estes grupos sociais vivenciam processos de cuidado com a terra e dela tiram seu sustento. Como bem nos traz Thum (2009) as práticas de conservação dos recursos naturais são passadas para as novas gerações exatamente porque são processos presentes nos modos de vida dos diferentes segmentos.

Manter viva estas comunidades é um desafio constante, considerando a retração de políticas públicas de apoio a estes grupos, bem como a ampliação das dificuldades históricas pelas quais os grupos passam cotidianamente, impactando diretamente no processo de tomada de decisão dos jovens quilombolas. Na visão de Simon (1965), o julgamento é inseparável da tomada de decisão, porque faz parte dela e implica pensamento e ação, que, por sua vez, são centrais no processo de tomada de decisão.

Para os jovens rurais quilombolas, a saída do meio rural, mesmo que em busca de ingresso no mercado de trabalho ou para viabilizar a continuidade nos estudos, não é uma escolha fácil, com bem reflete Ramos (1983), quanto à tomada de decisão, sendo, conforme o autor, um detalhe do processo de escolhas pessoais que determina como este se dará ou não, e esta decisão está fora do sistema de esforços que a constituem, ainda que seja objeto do processo.

E, pelo aspecto geográfico, entendendo que a geografia pode ser trabalhada por um par de categorias: de um lado a configuração territorial e, de outro, as relações sociais (SANTOS, 1988). A configuração territorial ou geográfica tem uma existência material própria, mas sua existência social, isto é, sua existência real, somente lhe é dada pelo fato das relações sociais, argumento que justifica o olhar no âmbito geográfico.

Ainda, resgatando Santos (1988), é possível entender que os movimentos da sociedade, atribuindo novas funções às formas geográficas, transformam a organização do espaço, criam novas situações de equilíbrio e, ao mesmo tempo, novos pontos de partida para um novo movimento. Entendimento que se aplica à dinâmica dos moradores quilombolas na zona rural de SantıAna do Livramento, onde as famílias, mesmo em risco de desaparecimento, em função da evasão dos jovens para o polo urbano, procuram estratégias e criam movimentos para manterem sua resistência. 


\section{Entendendo o desenvolvimento}

O desenvolvimento pode ser entendido como a evolução que nada tem de linear, e que pode se dar em diferentes direções, aproximando-se ou distanciando-se do ideal contido no projeto normativo do desenvolvimento como melhoria dos indicadores econômicos, sociais e ambientais (FAVARETTO, 2006). Assim, o desenvolvimento pode ser compreendido como um processo histórico de mudanças e transformações da sociedade ao longo do tempo. Vários foram os processos de desenvolvimento, mas, após a Segunda Guerra Mundial, os planos de reestruturação dos países europeus motivaram a implementação de processos semelhantes em outras partes do mundo, através de programas direcionados ao desenvolvimento. Embora haja uma diversidade conceitual, a ideia de desenvolvimento, até então, vinha sendo associada à ideia de crescimento econômico e progresso.

No âmbito da agricultura foi a partir da década de 50 que inicia uma nova compreensão do tema. Alicerçada no que foi genericamente intitulado de "revolução verde", apoiada na modernização, o mundo rural passou a subordinar-se a novos interesses (NAVARRO, 2004). No Brasil, esse período de modernização no campo pode ser visto com a crescente integração das atividades agrícolas aos complexos agroindustriais. Tal processo possibilitou acesso à tecnologia, políticas de crédito e assistência técnica. Uma década após a implantação dos projetos de desenvolvimento no Brasil, ficou claro o modelo extremamente seletivo e gerador de múltiplas desigualdades sociais, criando uma nova perspectiva conceitual de desenvolvimento.

O desenvolvimento rural pode ser visto por forças internas e externas à região em que os atores estão envolvidos, simultaneamente, em um complexo de redes locais e externas que podem variar significativamente entre regiões (KEGEYAMA, 2004). Já para Favaretto (2010) a ideia de desenvolvimento rural não é nova, sendo que esse processo passou por quatro grandes momentos: o primeiro marcado pelos projetos de desenvolvimento comunitário; o segundo pelos projetos de reforma agrária; o terceiro por projetos de desenvolvimento rural e integral e, por último, os projetos que falam em desenvolvimento territorial e combate à pobreza.

Já Navarro (2001, p.88) entende desenvolvimento rural como "uma ação previamente articulada que induz (ou pretende induzir) mudanças em um determinado ambiente rural". Ainda de acordo com o autor, as definições do termo desenvolvimento rural variaram durante o tempo, mas normalmente nenhuma das propostas exclui a melhoria do bem-estar das 
populações rurais como objetivo final desse desenvolvimento.

Nesse sentindo, o rural brasileiro passa por algumas transformações que, segundo Schneider (2010, p. 521), constituem:

[...] uma nova conformação econômica e demográfica que possui como característica fundamental a redução crescente das diferenças entre o urbano e o rural, especialmente no que se refere ao mercado de trabalho, devido ao crescimento da população ocupada em atividades não agrícolas. O rural deixa de ser "sinônimo de atraso" e se desconecta da agricultura, que passa a ser apenas uma de suas atividades.

Esse novo rural configura-se com famílias pluriativas, as quais articulam atividades agrícolas e não agrícolas, dentro e fora das propriedades. Essa mudança é ocasionada pela diminuição dos postos de trabalho no meio rural. "Portanto, o que se verifica é que o processo de modernização acarretou limites para os agricultores, os quais e acabam de inviabilizar a permanência no espaço rural, ou fazem das propriedades apenas local de morada" (SCHINEIDER, 2004, p. 89).

Para Wanderley (2000) o novo rural assume alguns aspectos novos, tais como: tornase atrativo para as categorias sociais urbanas; o desenvolvimento do rural dependerá das atividades agrícolas, mas também da capacidade de atrair novas atividades; modernização e aumento de rendas, o que proporcionam alguns privilégios antes somente no meio urbano; um olhar diferenciado através da valorização do patrimônio cultural e natural e os novos papéis que os agricultores possam assumir, os quais deverão contribuir para a preservação das paisagens rurais e para a guarda e reprodução das tradições culturais rurais, estendendo suas atividades profissionais para além do núcleo produtivo agrícola, tornando-se pluriativos.

Assim, novas práticas como administração de paisagem, conservação da natureza, turismo rural, produção orgânica fazem do desenvolvimento rural um processo multifacetado, onde as propriedades podem assumir novas formas, novos papeis e estabelecer novos elos com outros agentes (KAGEYAMA, 2004).

Portanto, tem-se que o processo de desenvolvimento rural vai além da análise do crescimento econômico, e outros aspectos podem ser determinantes nesse processo, tais como as questões ambientais, educacionais, de qualidade de vidas entre outros.

\section{Comunidades tradicionais}

Os povos e comunidades tradicionais são grupos culturalmente diferenciados. 
Segundo o Decreto 6.040, de 7 de fevereiro de 2007, os Povos e Comunidades tradicionais são definidos como

[..] grupos culturalmente diferenciados e que reconhecem como tais, que possuem formas próprias de organização social, que ocupam e usam territórios e recursos naturais como condição para sua reprodução cultural, religiosa, ancestral e econômica, utilizando conhecimentos, inovações e práticas geradas e transmitidos pela tradição.

E, a partir da conceituação, ainda expressa o território como espaço social fundamental, também previsto no Decreto 6040/2007, ainda em vigor, e que elenca a Política Nacional de Desenvolvimento Sustentável dos Povos e Comunidades Tradicionais, portanto os territórios destas comunidades são:

[..] os espaços necessários à reprodução cultural, social e econômica dos povos e comunidades tradicionais, sejam eles utilizados de forma permanente ou temporária, observado no que diz respeito aos povos indígenas e quilombolas, respectivamente, o que dispões os artigos $231 \mathrm{da}$ Constituição e 68 do Ato as Disposições Constitucionais Transitórias e demais regulamentações (Decreto 6040/2007).

No Brasil, devido à diversidade sociocultural, identificam-se como povos tradicionais os indígenas, os remanescentes de quilombos, os ribeirinhos, os ciganos, entre outros, e que a vida destes povos se faz a partir das relações com, entre e com os outros em um território.

De acordo com Little (2002, p. 23), a definição de povos tradicionais reúne elementos como a existência de regimes de propriedade comum, o sentimento de pertencimento a um lugar, a procura por autonomia cultural e práticas adaptativas sustentáveis. Esses grupos têm um modo de vida diferenciado, ou seja, estão ligados à tradição, cultura e hábitos que passaram de geração para geração.

Na visão de Diegues (2000), "sociedades tradicionais" são grupos culturalmente diferenciados que historicamente reproduzem seu modo de vida, de forma mais ou menos isolada, com base em modos de cooperação social e formas especificas. Esses povos e comunidades, ao longo da história, foram marcados pela exclusão, não somente por fatores étnico-raciais, mas pela impossibilidade de acessar as terras por eles tradicionalmente ocupadas. Fora esses conflitos de luta pela terra, as comunidades também enfrentam problemas com outros grupos sociais, como coloca Vieira (2014, p. 23):

A fronteira étnico-cultura surge quando a comunicação entre grupos, por exemplo, de comunidades tradicionais do tipo extrativistas, não conseguem estabelecer trocas inteligíveis de valores, sentimentos e práticas com as 
grandes indústrias que querem utilizar seus conhecimentos para uso comercial, ou quando um fiscal do IBAMA tenta fazer um ribeirinho entender que não pode construir à beira de um rio em que sempre morou por ser área de preservação permanente ou quando a constituição de uma unidade de conservação de proteção integral impede uma comunidade tradicional de extrair seu sustento em sua produção da floresta, conforme suas práticas tradicionais.

Nesse enredo de lutas por terras, reconhecimentos e problemas entre grupos sociais, emergem as comunidades quilombolas, que são consideradas comunidades tradicionais e, segundo o Decreto Federal nº 4.887, de 2003,

Consideram-se remanescentes das comunidades de quilombo, para fins deste decreto, os grupos étnico-raciais, segundo critérios de auto atribuição, com trajetória histórica própria, dotados de relações territoriais específicas, com presunção de ancestralidade negra relacionada à opressão histórica sofrida.

O que confirma o Art. 68 do Ato das Disposições Constitucionais Transitórias da Constituição Federal ao mostrar que indivíduos agrupados em maior ou menor número, que pertençam ou pertenciam a comunidades, que viveram, vivam ou pretendam viver nas condições de integrantes delas como repositório de suas tradições, cultura, língua e valores, historicamente relacionados ou culturalmente ligados ao fenômeno sociocultural quilombola. As comunidades quilombolas ganharam reconhecimento oficial da sua cultura, mas permanecem lutando por acesso e políticas de inclusão, ou seja, embora tenham forte arcabouço legal que as reconhece e protege as comunidades quilombolas ainda estão à margem de muitos direitos consignados, excluídas de políticas públicas de saúde, educação (vide não atendimento da lei federal 10.639), de segurança, uma vez que seus territórios estejam quase sempre sob ameaça.

Há, ainda, um forte elemento característico das comunidades tradicionais, que é o do uso equilibrado dos recursos naturais, voltado para a melhoria da qualidade vida, entendido como desenvolvimento sustentável. Por isso, no entendimento de Spamer (2017), os povos tradicionais exercem uma lógica de reciprocidade com a terra, com o seu território e com as outras formas de vida.

\section{Os saberes e a Teoria do Bem Viver}

É possível a harmonia entre desenvolvimento e a preservação e o respeito ao modo de vida das comunidades tradicionais. Este é um dos principais argumentos da Teoria do Bem 
Viver (Vivir Bién), e esta é a proposta defendida por Solón (2017), para quem o desenvolvimento é uma proposta construída pela sociedade, e não pelas instituições estatais. Para isso, o segredo seria o fortalecimento da comunidade e à potencialização de sua capacidade de complementariedade com outras comunidades e a autogestão do seu território (SOLON, 2017).

Para este teórico, o Estado não pode ser um organizador de toda a sociedade, e sim um fator que contribua com o empoderamento das comunidades e organizações sociais, através de práticas não clientelistas. Ou seja, no Bem Viver, as comunidades tradicionais são protagonistas de suas histórias e dos seus processos de desenvolvimento, e a elas caberia o provimento de construir suas próprias políticas, dentro de suas próprias realidades e peculiaridades, ao invés de esperar pela instrumentalização do Estado.

Ainda para Solón (2017), o empoderamento das comunidades deve dar-se aproveitando as práticas e os saberes ancestrais e combinando estes com as inovações tecnológicas, sempre e quando estes contribuam para fortalecer o equilíbrio entre a natureza e as comunidades tradicionais.

Na visão de Belaunde (2015), o Bem Viver nasce do território e, ao mesmo tempo, faz o território, apelando aos seus donos espirituais e suas histórias. "Para a autora, Bem Viver tem uma forte ligação com a palavra viver bem, concebida em termos causais como "fazer ouvir", "fazer pensar", "fazer alegrar", quem vive bem "faz crescer" suas crianças através do exemplo e da palavra. Ou ainda, viver bem é algo feito todos os dias, mesmo nos menores detalhes. (BELAUNDE, 2015, p.2) Com relação ao desenvolvimento, no entendimento de Escobar (2012), este continua contaminando a realidade social e permanece no centro de uma poderosa, porém frágil, constelação semântica. A ideia, para Escobar (2012), envolve uma oportunidade para construção coletiva de uma nova forma de pensar e de estilo de vida comunitário e social, o que traduz o Bem Viver como tentativa de reverter a colonialidade do poder, do conhecimento e do ser que caracterizou o mundo moderno. (ESCOBAR, 2012)

\section{Desenvolvimento a partir das liberdades}

O desenvolvimento pode ser visto como um processo de expansão da liberdade, 0 qual exige que se removam as principais fontes de privações, tais como a pobreza e a falta de oportunidades econômicas. Sen (2010), através da abordagem das capacitações, mostra a igualdade de oportunidades de os indivíduos exercerem suas liberdades de escolhas, ou seja, 
de levarem a vida que desejam. De acordo com Sen (2010), essa abordagem trata de avaliar os termos de habilidade real de um indivíduo alcançar vários funcionamentos de valor como parte de sua vida, uma vez que se tenta medir não os meios, mas os fins dos quais os funcionamentos de valores podem ser atingidos.

Um alicerce de toda a "economia filosófica" de Sen (2010) é a ideia de que a "vida boa" é uma vida com escolhas genuínas, na qual ninguém é forçado a viver de alguma forma específica, por mais rica que esta forma de vida possa ser sob outros aspectos (SEN, 2010). A realização liga-se ao que conseguimos fazer ou alcançar, a liberdade à oportunidade real que temos para fazer ou alcançar aquilo que valorizamos (SEN, 2010). Oportunidade é mais do que ter recursos, são capacidades de poder escolher, buscar, rejeitar situações. São as capacidades de os indivíduos exercerem suas liberdades, a liberdade de escolha está ligada com aquilo que podemos fazer e valorizamos. Ainda, de acordo com Sen (2013, p. 29) um número imenso de pessoas em todo mundo é vítima de várias formas de privações de liberdade. $\mathrm{O}$ autor ainda coloca que muitas pessoas têm pouco acesso a serviços de saúde, saneamento básico ou água tratada, e passam a vida lutando contra uma morbidez desnecessária, sucumbindo à morte prematura.

A capacidade de um indivíduo consiste nas combinações alternativas de funcionamentos cuja realização é factível para ele (SEN, 2013) e os funcionamentos podem variar desde os físicos, como estar bem alimentado e abrigado, até as mais complexas, como ser feliz, ter respeito próprio, ser aceito, tornar parte da comunidade e assim por diante .

$\mathrm{Na}$ medida em que os funcionamentos são característicos do bem-estar, a capacidade representa a liberdade de uma pessoa alcançar o bem-estar. Logo, a capacidade representa as várias combinações de funcionamentos dentre as quais o indivíduo pode escolher uma combinação.

Na visão seniana não importa o que as pessoas detêm, mas a liberdade de que elas realmente dispõem para escolher a vida que querem levar. É essa liberdade real que é representada pela "capacidade" de uma pessoa realizar as várias combinações que são alternativas de funcionamentos. Os recursos seriam os meios para a busca de qualquer possibilidade de escolha que levam esse indivíduo a vida que deseja ter.

Outra análise que pode ser feita mediante a teoria seniana é através dos intitulamentos, as capacidades que são retidas ou ampliadas. Assim como no trabalho de Costa et al. (2017), os intitulamentos utilizados neste trabalho estão relacionados com 
elementos do contexto social que favorecem ou não a ampliação das capacidades dos indivíduos. Neste sentindo, o desenvolvimento vai além da decisão individual (funcionamentos), mas depende também dos aspectos estruturais que envolvem esse indivíduo. De acordo com Sen (2010, p.235).

[...] intitulamentos incluem capacidades aplicadas ao espaço de mercadorias: a capacidade (quer dizer, o conjunto capacitório) de uma pessoa é um "conjunto de pacotes alternativos de funcionamentos", o intitulamento, "um conjunto de pacotes alternativos de mercadorias.

Portanto, os intitulamentos representam as várias oportunidades que os indivíduos podem acessar tais como saúde, educação, infraestrutura, etc. Esses intitulamentos empoderam os indivíduos para realizar suas escolhas através das capacidades, que refletem as liberdades substanciais dadas as oportunidades que são escolhas diante das comparações interpessoais de vantagens. No que se refere à realização e liberdade, a primeira refere-se ao que conseguimos fazer ou alcançar, já a segunda, a liberdade, refere-se à oportunidade real que se tem para alcançar aquilo que valorizamos. Nesse sentindo, as desigualdades podem ser vistas em relação a ambas. Sen (2010) coloca que a distinção entre realização e liberdade é bastante central para a avaliação social. Portanto, o desenvolvimento constitui um processo diretamente relacionado com a expansão e garantia de liberdade para todas as pessoas liberdade de escolha e de agir.

\section{Procedimentos metodológicos}

O presente trabalho teve definido o Estudo de Caso como método de pesquisa, sendo desenvolvido junto às trinta e uma famílias, e, em especial, junto aos integrantes jovens destes núcleos e à liderança quilombola. A coleta de dados foi feita a partir de entrevistas semiestruturada, observação participante de anotações realizadas em campo, com a realização posterior de descrição do contexto analisado. Foram utilizadas, ainda, outras técnicas complementares, quais sejam: audição das narrativas, histórias de vida e diários de campo, o que poderá remontar, a partir das falas dos entrevistados, sua percepção quanto à identidade e o potencial de desenvolvimento da comunidade do Ibicuí.

Nas palavras de Yin (2010), o estudo de caso é preferido no exame de eventos contemporâneos, quando os comportamentos relevantes não podem ser manipulados. O método, segundo o autor, conta com muitas das mesmas técnicas que a 
pesquisa histórica, mas adicionam duas fontes de evidência geralmente não incluídas no repertório do historiador, quais sejam: observação direta e entrevistas das pessoas envolvidas nos eventos (YIN, 2010).

E, como se trata de pesquisa social crítica, Richardson (2008) colabora ao afirmar que primeiro é essencial estudar o desenvolvimento histórico de um fenômeno para apresentar mudanças em sua conceituação através do tempo, para além de registrar mudanças em sua aparência ou essência, mas também revelar a natureza dinâmica da relação entre a aparência e a essência do fenômeno. No âmbito da pesquisa a que se dedica este estudo, Richardson (2008) traz que a escolha do local adequado e a familiaridade do pesquisador com os membros do grupo são aspectos fundamentais da pesquisa qualitativa, o que vem ao encontro do que se propõe a investigar na comunidade quilombola rural de Sant'Ana do Livramento, inserindo a pesquisadora naquele meio, junto às famílias investigadas, obtendo, de cada entrevista, uma melhor percepção do problema que se impõe.

Conforme atesta o autor, o investigar qualitativo está mais preocupado com a validade das informações coletadas, isto é, se os dados expressam autenticamente a visão dos entrevistados, com interferência mínima do processo de pesquisa. Esse é, segundo Richardson (2008), o critério de validade, a capacidade de o pesquisador ter acesso às autênticas opiniões dos entrevistados. Todos estes elementos servem para subsidiar o aspecto metodológico adotado no referido estudo.

\section{Universo da pesquisa e amostra}

A população alvo deste estudo é composta de trinta e um núcleos familiares rurais, e especialmente os integrantes jovens das famílias destes grupos nos quais estes indivíduos são de extrema relevância para a pesquisa, por serem todos descendentes de pessoas em situação de escravidão, de etnia negra. São protagonistas do conflito de decidir pela permanência na comunidade rural quilombola, cujas perspectivas de desenvolvimento são investigadas, relacionando estas potencialidades com os cenários favoráveis ao desenvolvimento destas comunidades e a permanência dos jovens no campo.

Técnica de coleta de dados

Foram utilizados na pesquisa, a fim de coletar os dados pretendidos, os procedimentos de observação e entrevista. A observação assume, geralmente, a forma de 
observação participante que se caracteriza pelo contato direto do pesquisador com o fenômeno estudado, com a finalidade de obter informações acerca da realidade vivenciada pelas pessoas em seus próprios contextos (FLICK, 2010).

Já a entrevista deve obedecer ao caráter informal quando, na sua caracterização, sendo útil para verificar o que as pessoas sabem, pensam, creem, aspiram e temem, bem como comparar essas percepções com as de outras pessoas. As entrevistas informais, embora pareçam ser as mais fáceis de ser conduzidas, a rigor, são as mais difíceis, pois questões de natureza ética e de controle emergem a cada entrevista. (FLICK, 2010 apud FETTERMAN, 1989).

Técnicas de análise de dados

A análise dos dados, no presente Estudo de Caso, tem início no momento em que o pesquisador seleciona o problema e só termina com a redação da última frase de seu relatório. Foram observados os diagnósticos resultantes das entrevistas semiestruturadas, observações, anotações (diários de campo), conversas informais durante as visitas, registros fotográficos e em narrativas produzidas pelos moradores da comunidade objeto deste projeto. Temos, então, a seguir, a concepção expressa pelos jovens rurais quilombolas durante o procedimento de coleta de dados para a pesquisadora.

\section{O que pensam estes jovens da comunidade rural?}

A comunidade remanescente de quilombo do Ibicuí d'Armada está localizada na zona rural do município de Sant'Ana do Livramento, cujas famílias ocupam uma área total de 464 hectares, considerado território negro, pela ocupação da etnia. Neste local, Ibicuí d'Armada, residem 31 famílias quilombolas junto aos demais pequenos e grandes proprietários rurais. Nas famílias quilombolas são encontrados doze jovens, em sua maioria do sexo feminino, com idades que variam dos quatorze aos vinte anos e que, conforme demonstra o estudo, não vislumbraram potencialidades para permanência no campo.

Neste sentido, surge uma preocupação, as quais poderão comprometer a perenidade e a resistência desta comunidade rural quilombola em Sant'Ana do Livramento. Conforme o relato da líder social que preside a Associação de Moradores Quilombolas do Ibicuí d'Armada, ratificada por demais lideranças comunitárias rurais, houve iniciativas e trabalhos de grupo no início de 2016, para questionar, junto aos jovens, o que estava faltando e, nesta 
oportunidade, foi discutido o quanto é difícil envolver o jovem rural quilombola para que o mesmo se interesse pelas questões da comunidade onde o mesmo está inserido, discuti-las e procurar soluções.

A maioria dos jovens, segundo a Presidente da Comunidade, não quer trabalhar nem se manter no campo. Conforme a liderança rural, "eles querem vir pra cidade, porque não veem possibilidade de melhora no trabalho do campo". Em relação à possibilidade de trabalho com patrimônio histórico e cultural, levantada através das conversas com a liderança e com os jovens, ela é ignorada pelos jovens, que desconhecem este leque opcional de preservação do patrimônio quilombola.

A ideia das lideranças é construir um galpão, com maquinário disponível, que facilite o trabalho do jovem quilombola, tornando a permanência no campo mais atraente, o que garantiria que a sucessão familiar mantivesse a comunidade quilombola viva. A falta de acesso à tecnologia, amenizada recentemente com a conquista de um ponto de acesso digital na sede da comunidade e a única escola daquele distrito que possui turmas até o quinto ano do fundamental, também seriam outros fatores desencadeadores do desinteresse do jovem pela permanência na propriedade. Eles se queixam de falta de acesso à internet, principalmente ao mundo das redes sociais, o que não acontece quando se deslocam para zona urbana.

No mesmo diálogo, foi exemplificado pelas lideranças o caso de uma família cujo patriarca é sozinho, os filhos emigraram para a cidade e até tinham interesse em seguir no campo, mas, por resistência do pai em adequar-se às novas tecnologias para o trabalho no campo, e, consequentemente, o conflito de gerações, os filhos acabaram mudando pra zona urbana em busca de trabalho e não cogitam voltar pra comunidade quilombola.

Segundo a liderança, estes sucessores estão na cidade, em zona urbana, trabalhando em funções do comércio e prestação de serviços, algo totalmente desvinculado diretamente da vida rural e totalmente descolado das suas tradições familiares.

Existe, na opinião das lideranças, muita resistência dos mais velhos em aceitar as novas ideias dos filhos jovens, que, por falta de apoio dos pais, optam pela vida na cidade. "Isso é um risco para a existência da comunidade quilombola" diz a Presidente da Comunidade, inclusive, lembrando que muitos descendentes poderão vender suas terras, desfazendo a característica única do quilombo, uma vez que ainda não existe a titulação pelo INCRA, e sim pela Fundação Cultural Palmares, o que não impediria o comércio das terras. 
Toda a percepção explicitada pelas lideranças rurais quilombolas faz eco às ideias de Sen (2010), no que tange às análises de bem estar e desenvolvimento, lembrando que o teórico desconstruiu o paradigma de que padrão e qualidade de vida estejam ligados ao desenvolvimento econômico unicamente, e sim a capacidade dos indivíduos de utilização de bens (capital, força de trabalho, posses) em realização (SEN, 2010).

E para à construção desta "realização", que possa potencializar a presença do jovem quilombola em sua comunidade, na opinião das lideranças, faz-se preciso ouvir o jovem, seus anseios e aspirações, para tornar o campo atrativo. A ausência de uma liderança juvenil que promova conversas entre seus contemporâneos foi levantada pela líder comunitária como outro fator desmotivador da presença do jovem quilombola no território rural negro.

Já a percepção dos jovens quilombolas rurais, conforme suas narrativas e depoimentos traduz a consciência da importância da comunidade e ainda prevalece a vontade de retornar ao campo depois do término dos estudos. Segundo um dos relatos, a jovem quilombola afirma ter ideia da importância da comunidade, uma vez que a mesma contribui para a história, mostrando como foram atingidas várias conquistas pelos quilombolas e, ainda, expondo as diferenças culturais.

Ao todo foram ouvidos doze jovens rurais quilombolas, ainda moradores da comunidade rural negra, que pensam, em sua totalidade, na transferência para zona urbana, a fim de concluir os estudos do ensino médio, e, entre eles, apenas um jovem diz preferir ficar na cidade, enquanto os demais ainda não têm opinião completamente clara sobre o assunto, o que sinaliza a possibilidade de continuidade na existência de remanescentes quilombolas na zona rural.

Os jovens foram questionados quanto à percepção da importância cultural e histórica da comunidade quilombola no município, manifestando-se, em sua maioria, conscientes da relevância da comunidade no contexto histórico, cultural e humano. Uma das entrevistadas mencionou, inclusive, as tradições dos antepassados, mantidas geração após geração, pelas famílias quilombolas rurais.

Também foram questionados quanto à existência e atuação de liderança comunitária, capaz de manter os jovens interessados e atraídos pelas potencialidades de desenvolvimento rural, ao que responderam, em sua totalidade, que a atual presidente da Associação de Moradores Quilombolas cumpre este papel, defendendo o desenvolvimento da comunidade quilombola. 


\section{Considerações finais}

Este artigo teve como objetivo compreender os processos de resistência e perenidade das famílias em território negro quilombola, no distrito do Ibicuí d'Armada, localizado na fronteira oeste do Rio Grande do Sul.

Para atingir este objetivo foi adotada a abordagem qualitativa estudo de caso, com entrevistas com grupo de jovens moradores do território quilombola, bem como com a líder da comunidade e com o auxílio de outras técnicas de pesquisa, tais como anotações (diários de campo), conversas informais durante as visitas, registros fotográficos e narrativas produzidas pelos moradores da comunidade objeto deste estudo. Os jovens foram receptivos à pesquisa, promovendo narrativas, depoimentos e informações baseados nas suas vivências do campo e respectivas perspectivas de futuro. Pode-se constatar que a comunidade remanescente quilombola possui extrema riqueza cultural e histórica para o município, possuindo potencial ainda não explorado para alavancar desenvolvimento rural, cultural, social e humano.

Com os depoimentos, verificou-se que, embora de grande legado histórico e cultural, e com potencial para o desenvolvimento, a comunidade remanescente de quilombo carece ser atendida pelo poder público local, que sequer atende aos dispositivos da lei federal 10.639/03, que estabelece as diretrizes e bases da educação nacional, para incluir no currículo oficial a temática "História e Cultura Afro-brasileira", conforme afirmativa da líder quilombola.

O que nos reporta ao pensamento de Sen (2010), ao afirmar que, para que o desenvolvimento humano se consolide, é preciso manter e respeitar a cultura nativa. Ainda de acordo com o teórico, o poder esmagador da cultura e o estilo de vida ocidental (entendase americanizado), solapam o estilo e o modo de vidas tradicionais, portanto, para ele, reconhecer a diversidade encontrada em diferentes culturas é muito importante para o desenvolvimento no mundo contemporâneo, o que ratifica a importância da adoção de leis como a 10.639/03, que impacta na autoestima das comunidades negras, e transversaliza com a importância que os jovens quilombolas atribuem a sua comunidade e a existência da mesma.

E os jovens rurais quilombolas manifestaram possuir a vontade de permanecer no campo, mas, para potencializar o desenvolvimento destes meninos e meninas num cenário atualmente pouco atrativo na zona rural, entende-se como necessária e urgente a adoção de 
medidas que promovam maior perspectiva de futuro, para que a permanência na terra se concretize, bem como alguns tópicos elencados no artigo, quais sejam: busca de investimentos humanos e financeiros para criar mecanismos culturais, de atração folclórica e histórica, trabalho na autoestima daqueles jovens, instrumentalização mecânica para trabalho no âmbito rural, dentro dos princípios da teoria do Bem Viver e da teoria das capacitações.

\section{Referências}

ADÃO, Sebastião Cerqueira; MADRID, Rosemeri da S. Ações Empreendedoras do Governo Municipal de Sant'Ana do Livramento na Comunidade Remanescente de Quilombo do Ibicuí d'Armada. SOBER, 2015.

BRASIL. Constituição Federal. Brasília: Congresso, 1988.

BRASIL. Ato das Disposições Constitucionais Transitórias (ADCT) n 68 - Direito de propriedade à terra de comunidades remanescentes de quilombos.

BRASIL. Lei Federal 12.288, de 20 de Julho de 2010, Institui o Estatuto da Igualdade Racial.

BRASIL. Lei Estadual 13.694, de 19 de janeiro de 2011, Institui o Estatuto da Igualdade Racial e dá outras providências.

BRASIL. Lei 10,639, de 2003, que Estabelece as diretrizes e bases na educação nacional, para incluir no currículo oficial da rede de ensino a obrigatoriedade da temática "História e cultura afro-brasileira".

BRASIL. Secretaria Nacional de Políticas de Promoção da Igualdade Racial (SEPPIR). Disponível em: http://www.seppir.gov.br/ações/pbq

BRASIL. Quilombos no Brasil, Revista Palmares. Fundação Cultural Palmares, 2000. P 10 e 39. Disponível em: http://www.palmares.gov.br/revista/.

BELAUNDE, Luisa Elvira Viviendo bien: género y fertilidade entre los Airo Pai de la Amazonía Peruana. Lima: CAAAP. 2001.

CACHAPUZ. J.M.S. O Panorama Setorial da Bovino Cultura de Corte Gaúcha no processo de integração do Mercosul. Porto Alegre, EMATER/RS, 1993. 29p. EMATER RIO GRANDE DO SUL, REALIDADE RURAL, edição 7.

COSTA, Heloisa Helena Fernandes Gonçalves da; CARDOSO, Luciana Silveira. Por uma Política de Gestão para Museus. Cadernos NAUI, vol. B, n. 4, jan-jun. 2014. Disponível em: http://www.icomos.org.br/001_001.html. Acessado em novembro de 2018. 
COUCEIRO, Sylvia; BARBOSA, Cibele. Patrimônio Imaterial: Debates Contemporâneos. Disponivel em: https://pt.scribd.com/doc/279868601/patrimonio-debates-contemporaneospdf Acessado em dezembro de 2015.

ESCOBAR, Arturo. La Invención Del Desarrollo. Editoral Universidad El Cauca. Popayán. Colombia, 2012.

FLICK, Uwe. Introdução à pesquisa. 3. ed. Porto Alegre: Artmed, 2009

FUNDAÇÃO Cultural Palmares. Disponível em: http:// www.palmares.gov.br/?page id=37551. Acessado em 20 e 29 de novembro de 2018

IBGE - Instituto Brasileiro de Geografia e Estatística. Pesquisa Nacional por Amostra de Domicílios (PNAD), 2009.

INCRA. Instituto Nacional de Colonização e Reforma Agrária. Disponível em: http// www.incra.gov.br/quilombola. Acessado em 2 de maio de 2019.

IPHAN. Instituto do Patrimônio Artístico e Histórico Nacional. Disponível em: http:// www.iphan.gov.br Acessado em 28 e 29 de novembro de 2018.

JUNIOR, Sylvio Norton Gonzálvez de Moura; OLIVEIRA, Francisco Correia de. Quilombos como novo modelo de desenvolvimento, tendo a comunidade como prioridades: um estudo de caso na Associação Remanescente de Quilombo de Alto Alegre e adjacências. Ceará, 2010.

LEITE, Ilka Boaventura. Os Quilombos no Brasil: Questões Conceituais e Normativas. NUER/UFSC/CNPq/Fundação Ford, 2000.

LOPES, Nei. Enciclopédia Brasileira da Diáspora Africana. São Paulo: Selo Negro, 2004.

MOURA, Clóvis. Os negros e o sistema educacional brasileiro. Jornal Banto Nagô, Salvador, Grupo Cultural Olodum.

NASCIMENTO, Abdias. O quilombismo. Petrópolis: Vozes, 1980.

NAVARRO, Zander. Desenvolvimento rural no Brasil: os limites do passado e os caminhos do futuro. Estudos Avançados, v. 15. São Paulo.

PIRES, André. Um sentido dentro outros possíveis: o rural como representação. In: CAMPANHOLA, C; GRAZIANO DA SILVA, J.(Ed) O novo rural brasileiro - novas ruralidades e urbanização. v 7. Brasília: Embrapa Informação Tecnológica 2004, p-149-174.

PORTO, Rafael Gastal. Caracterização da Pecuária Familiar na Região da Campanha Meridional, Estudo de Caso no município de Bagé-RS. Pelotas: UFPEL, 2008. 
RIBEIRO, Anderson. A História da África nos Bancos Escolares. Representações e imprecisões na literatura didática. Disponível em:

http://www.scielo.br/pdf/eaa/v25n3/a03v25n3.pdf . Acessado em dezembro de 2018. RUA, Maria das Graças. Políticas Públicas. Florianópolis: Departamento de Ciências da Administração, UFSC, 2009.

SEN, Amartya. Desenvolvimento como liberdade. São Paulo, 2010.

YIN, Robert K. Estudo de Caso: planejamento e métodos. 4. Ed. Porto Alegre: Bookman, 2010.

\section{Detalhes das autoras}

Rosemeri da Silva Madrid

Mestrado em Administração, Especialização em Desenvolvimento, Universidade Federal do Pampa. E-mail: rosemeri.madrid@gmail.com.

Margarete Lesina Lopes Gonçalves

Doutoranda em Desenvolvimento Rural/Universidade Federal do Rio Grande do Sul, Mestrado em Economia pela Pontífice Universidade Católica do Rio Grande do Sul. E-mail: margaretelg@gmail.com. 